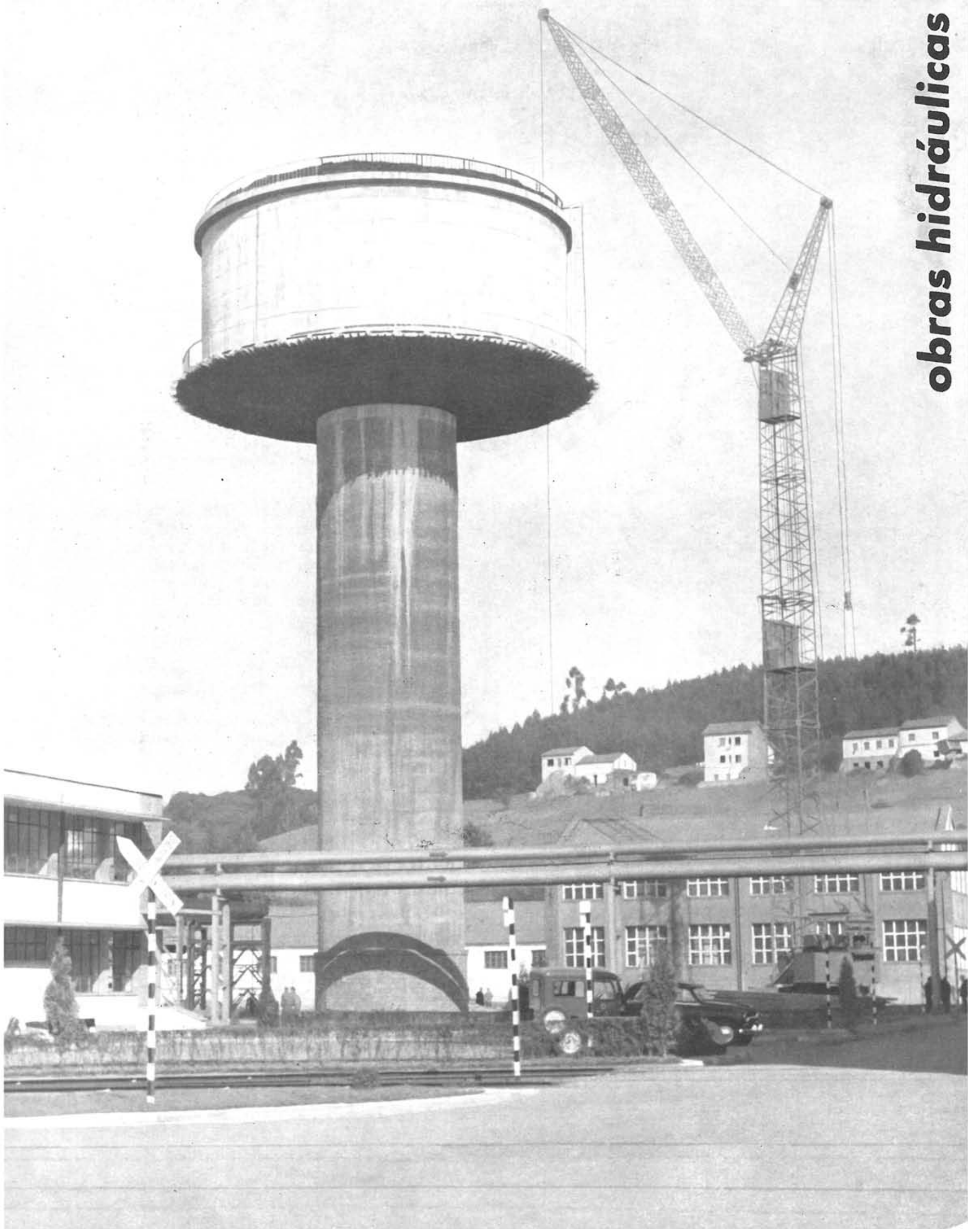




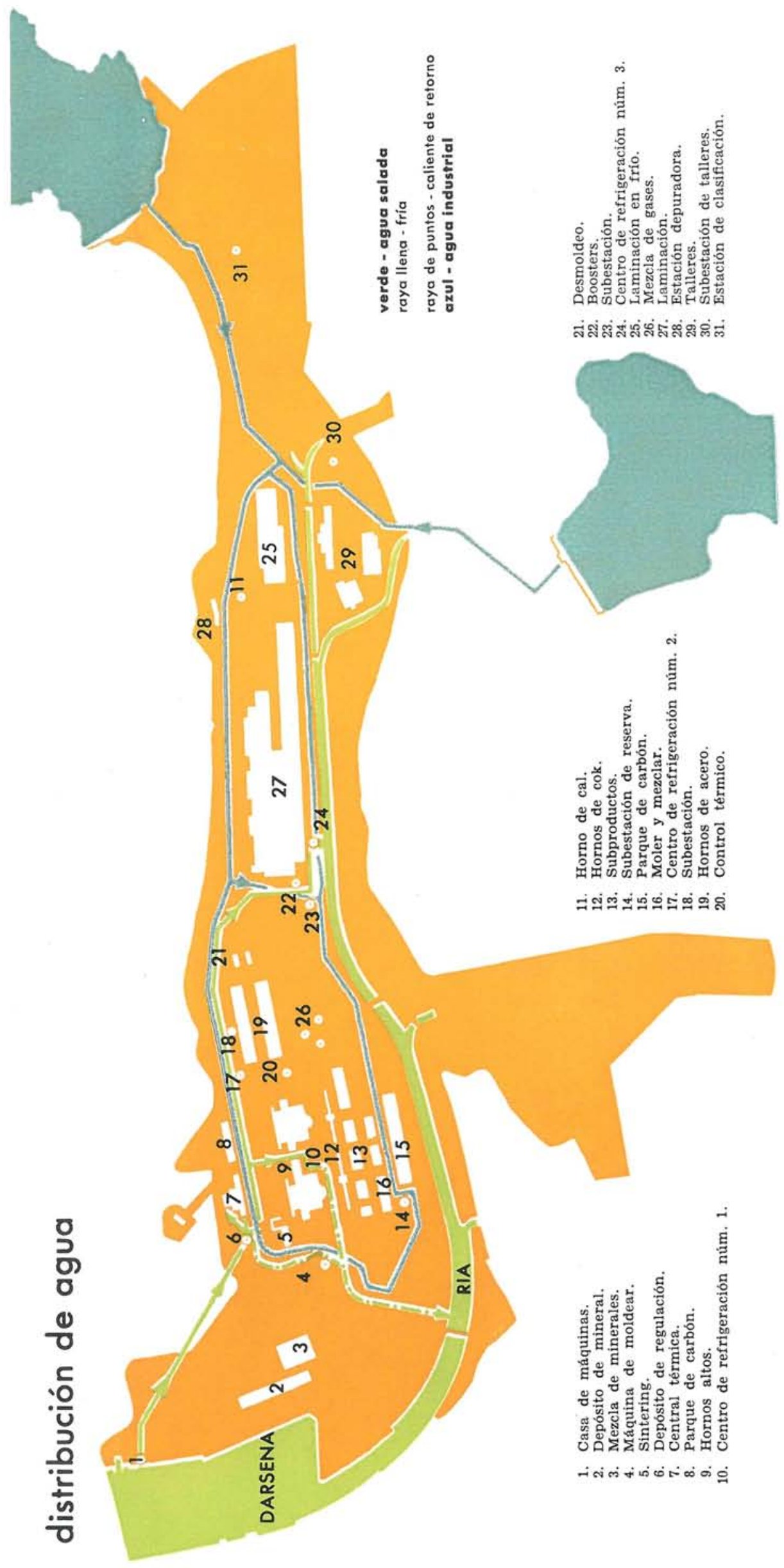

$530 \cdot 22$

Dada la vital importancia de este suministro para todos los elementos de la planta siderúrgica de Avilés, antes de conocer con exactitud las necesidades totales de agua dulce se hizo un estudio completo de cantidades y calidades de agua de los ríos más próximos: Gozón, Corvera, Arlós y Magdalena, que afluyen a la ría de Avilés.

Para ello, se realizaron análisis químicos y bacteriológicos de las aguas, se construyeron estaciones de aforos en todos los ríos mencionados, y se estudió la posibilidad de regulación de caudales.

Una vez conocidas las características de los ríos, curva de caudales, coeficiente de escorrentía, etc., se vió que, incluso para necesidades mínimas de la Factoría, era necesaria una regulación de las aportaciones de los mismos.

Estas aportaciones en año medio son las siguientes:

Río Gozón: $6,1 \mathrm{Hm}^{3}$, con embalses posibles en cuenca afluente.

Río Corvera: 12,3 $\mathrm{Hm}^{3}$, con embalses posibles en su cuenca.

Río Arlós: $8,2 \mathrm{Hm}^{3}$, con embalses posibles en su cuenca.

Río Magdalena: $10,7 \mathrm{Hm}^{3}$, con embalses posibles en su cuenca.

Ante las concesiones que de los ríos Arlós y Magdalena tiene el Ayuntamiento de Avilés, teniendo en cuenta el natural incremento que debería experimentar esta población, se estimó conveniente dejar las aguas de estos ríos para el abastecimiento de Avilés y se ampliaron los estudios hidrológicos a cuencas más caudalosas y más alejadas de la Factoría, con objeto de prever las necesidades mencionadas. 
Consiste en un cilindro de $9,00 \mathrm{~m}$ de altura y $18,44 \mathrm{~m}$ de diametro, con capacidad interior para $1.600 \mathrm{~m}^{3}$ de agua, elevado $30 \mathrm{~m}$ sobre el suelo sobre un fuste circular hueco de $7 \mathrm{~m}$ de diámetro exterior, en el interior del cual van alojadas las tuberías del depósito $y$ una escalera de acceso al mismo.

La estructura resistente del depósito está formada por 24 marcos en $U$ horizontales que sobresalen en voladizo del cuerpo cilíndrico interior, $y$ arriostrados con un tirante. Este tirante se ha sometido a una pre-tensión hormigonándose mientras estaba atirantado por una carga igual a la mitad del peso del agua que había en el interior del depósito. Con ello se pretenden cortar grietas que se producirian en el hormigón del tirante con el peligro
de ataque de la armadura del mismo.

Los ríos estudiados fueron: el Nora, el Narcea y el Nalón. Estos dos últimos rios, por sí solos y sin regulación, tienen también caudal suficiente para abastecer ampliamente las necesidades de la Siderúrgica.

Una vez concretadas las necesidades de agua y conocidas las posibilidades de todos los ríos mencionados, se llevó a cabo un estudio económico de los sistemas posibles considerando los aumentos progresivos de demanda de la Factoría y adaptando la ejecución de las obras necesarias de abastecimiento al desarrollo en distintas etapas de la misma.

El plan general hidráulico se divide en los siguientes grupos:
A) Captación de ríos y regulación de caudales.
B) Conducción de aguas a la Factoría.
C) Depuración de las aguas.
D) Red de distribución general a la Factoría.
E) Circuito de agua dulce en los distintos departamentos.
F) Redes de colectores.

El estudio económico del abastecimiento de agua, teniendo en cuenta los distintos grupos mencionados, hizo evidente la necesidad de recuperar la mayor cantidad posible de agua, resultando, por tanto, la necesidad de que todos los circuitos posibles de los departamentos de hornos altos de cok, hornos de acero, laminación, etc., fueran cerrados, necesitando, por lo tanto, refrigerar sus aguas.

El tipo elegido para refrigeración de agua dulce fué el de cambiadores de calor, utilizando como refrigerante el agua salada. Esta solución se consideró la más conveniente por el emplazamiento de la Factoría, junto a la ría de Avilés: teniendo en cuenta, además, que el abastecimiento de agua salada era necesario hacerlo independientemente para la refrigeración de la Central Térmica, cuyos consumos serán superiores a $\operatorname{los} 10 \mathrm{~m}^{3}$ por segundo.

Por todo ello, a los grupos indicados del Plan General Hidráulico, hay que añadir los siguientes:

G) Abastecimiento de agua salada.

H) Distribución general de agua salada y a cada centro de refrigeración.

I) Centros de refrigeración y Centrales de bombeo.

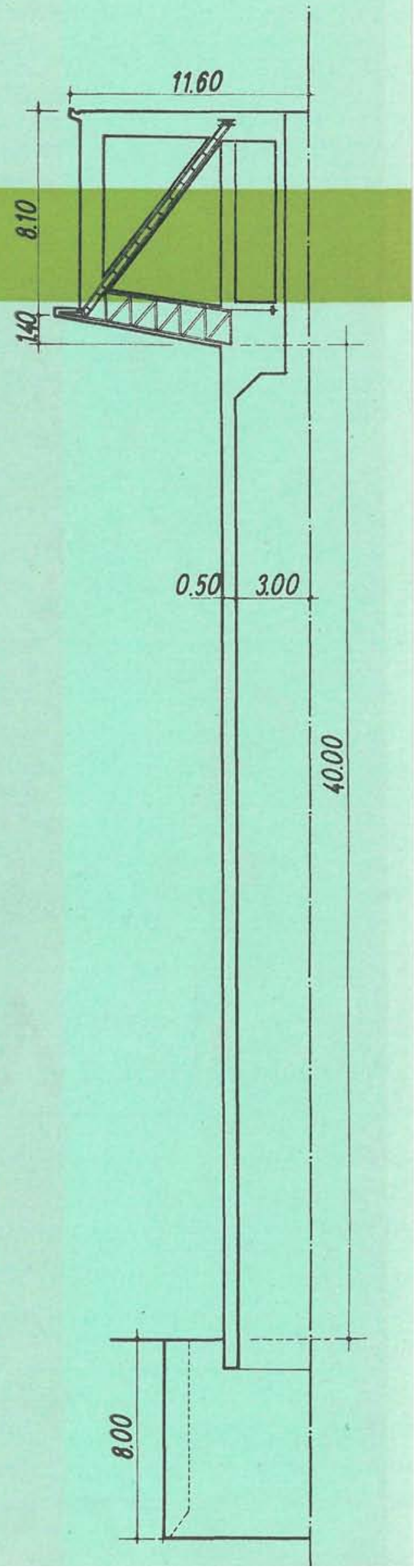




\section{embalse de La Granda}

El río Gozón no posee en toda su cuenca un lugar apropiado para regular sus aguas; por ello,

y aprovechando un valle normal a él, el del Arroyo de la Granda, próximo al emplazamiento de la Factoría,

que ofrece

características de impermeabilidad, capacidad y cerrado adecuados,

se ha construído un embalse que recoge las aguas de este río y su afluente el Requejada $y$, de esta forma,

se regulan en su totalidad.

Se han construído las obras de toma correspondientes a ambos ríos, azud de desviación, bocal, regulador

y dos canales de conducción que llevan las aguas a un tercero, común, que las transporta al embalse de La Granda.

Los canales tienen las siguientes características:

Canal de Requejada: capacidad, $0,5 \mathrm{~m}^{3} / \mathrm{s}$; longitud, $180 \mathrm{~m}$.

Canal del Gozón: capacidad, $2,0 \mathrm{~m}^{3} / \mathrm{s}$; longitud, $2.800 \mathrm{~m}$.

Canal común: capacidad, $2,5 \mathrm{~m}^{3} / \mathrm{s}$; longitud, $1.100 \mathrm{~m}$.

La capacidad de embalse necesario para la regulación de estos caudales es de $2,1 \mathrm{Hm}^{3}$. 


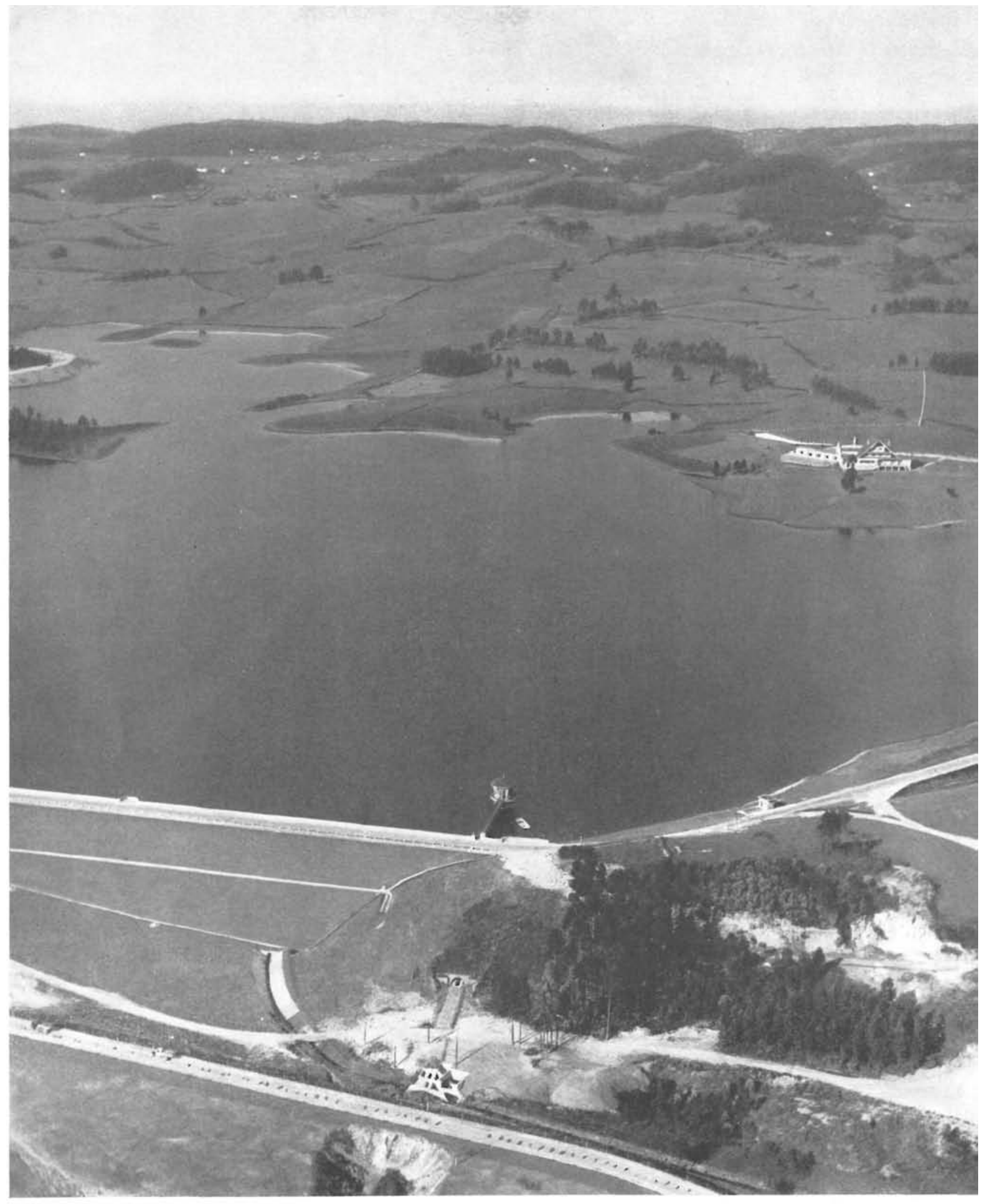

El embalse de La Granda se construyó con una capacidad útil de $3,8 \mathrm{Hm}^{3}$, teniendo en cuenta la regulación conjunta de los tres ríos Gozón, Nora y Corvera.

La presa ejecutada es de $19 \mathrm{~m}$ de altura. En líneas generales, consta de un núcleo arcilloso de tierras impermeables que tiene por misión el impedir el paso del agua. 


\section{presa de La Granda}

La resistencia estructural de la presa se debe, preferentemente, a los espaldones de tierras semipermeables y permeables de mayor rozamiento interno que la del núcleo. Este núcleo llega hasta el terreno natural compacto, donde se dispone un rastrillo de hormigón armado.

La toma de agua se hace por medio de una torre, con dos tomas, de donde pasa el agua a dos tuberías alojadas en un túnel, construído en la ladera, evitando el peligro de filtraciones.

El aliviadero de labio fijo se ha construído en el canal común de traída de las aguas al embalse.
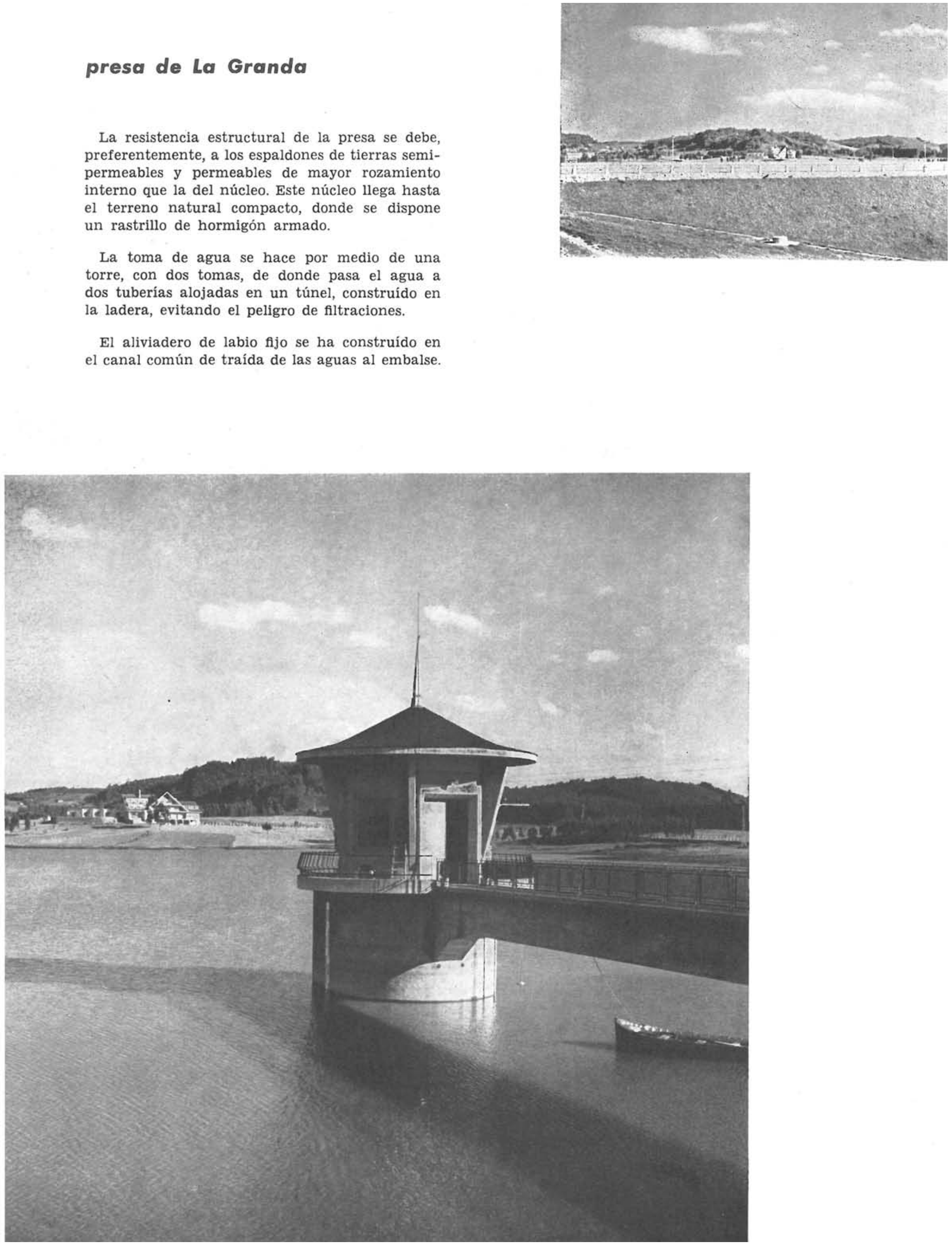


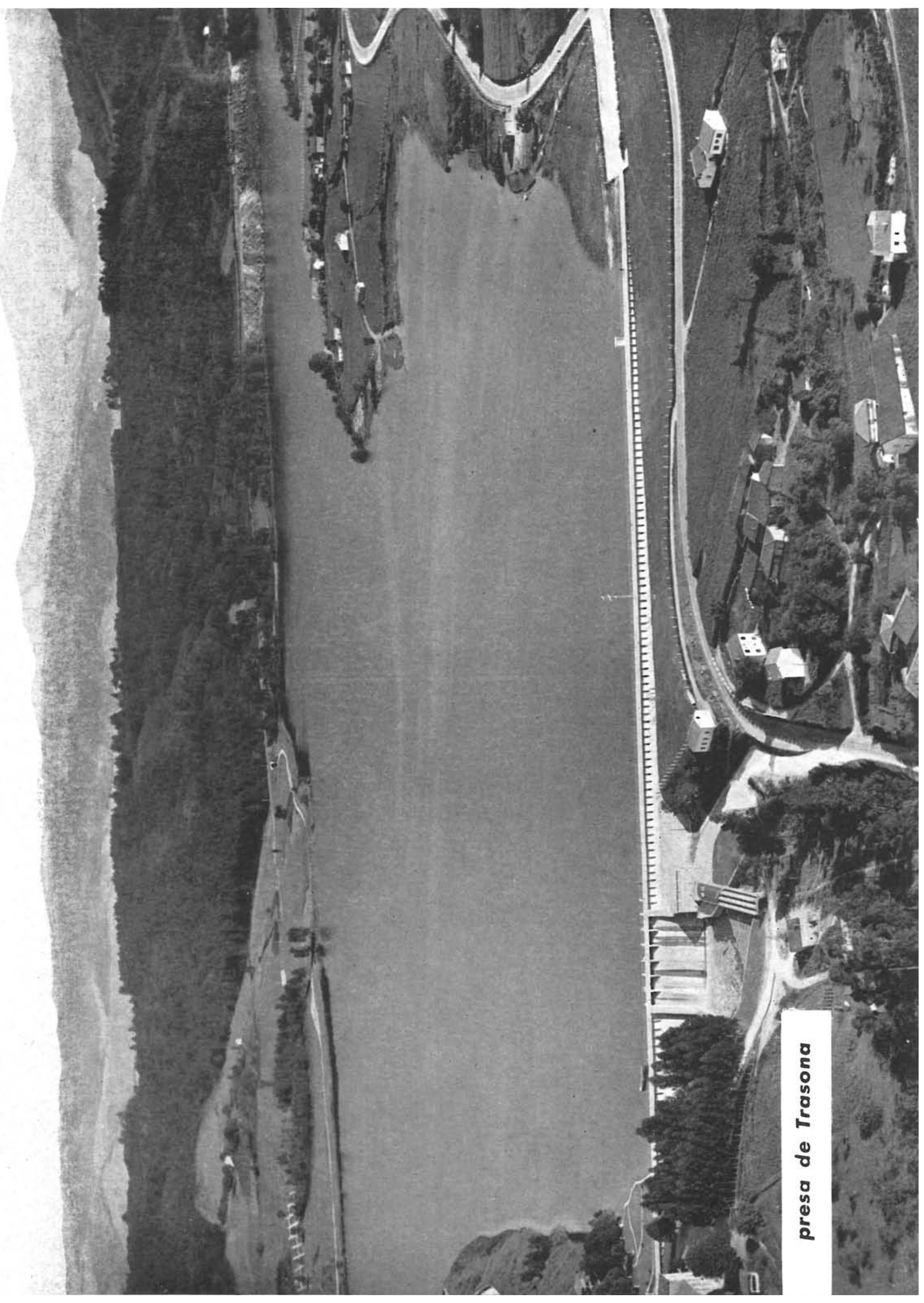



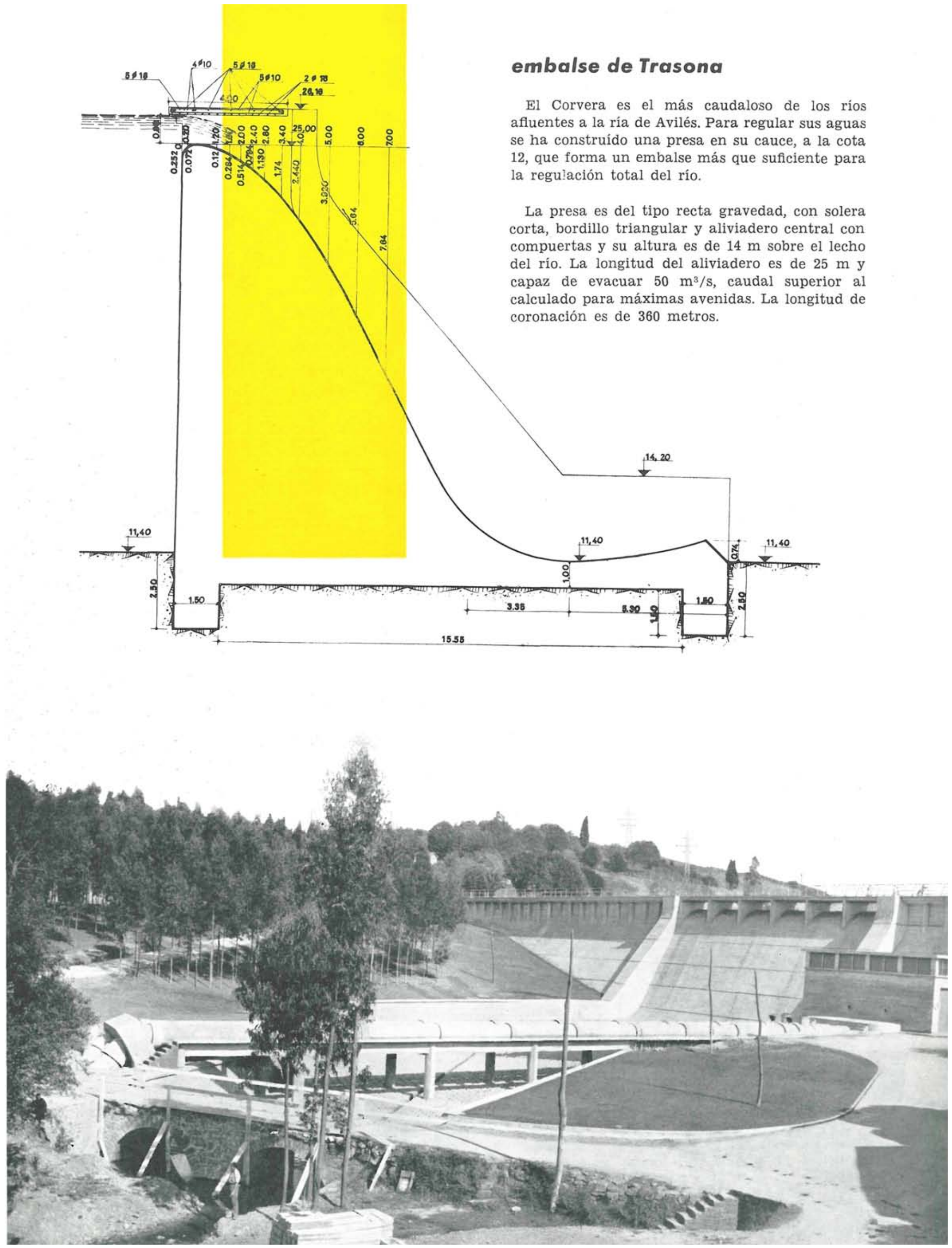


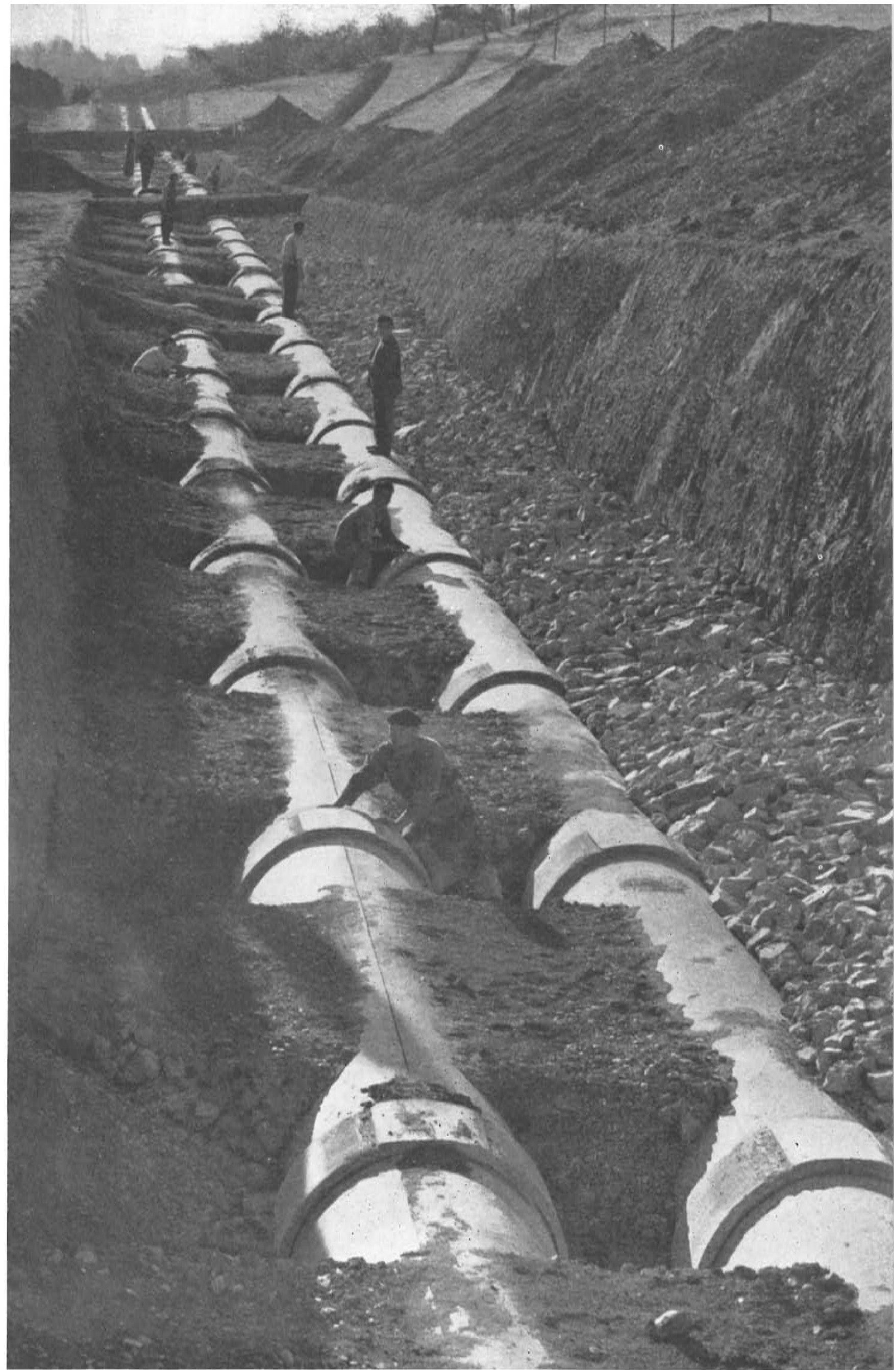




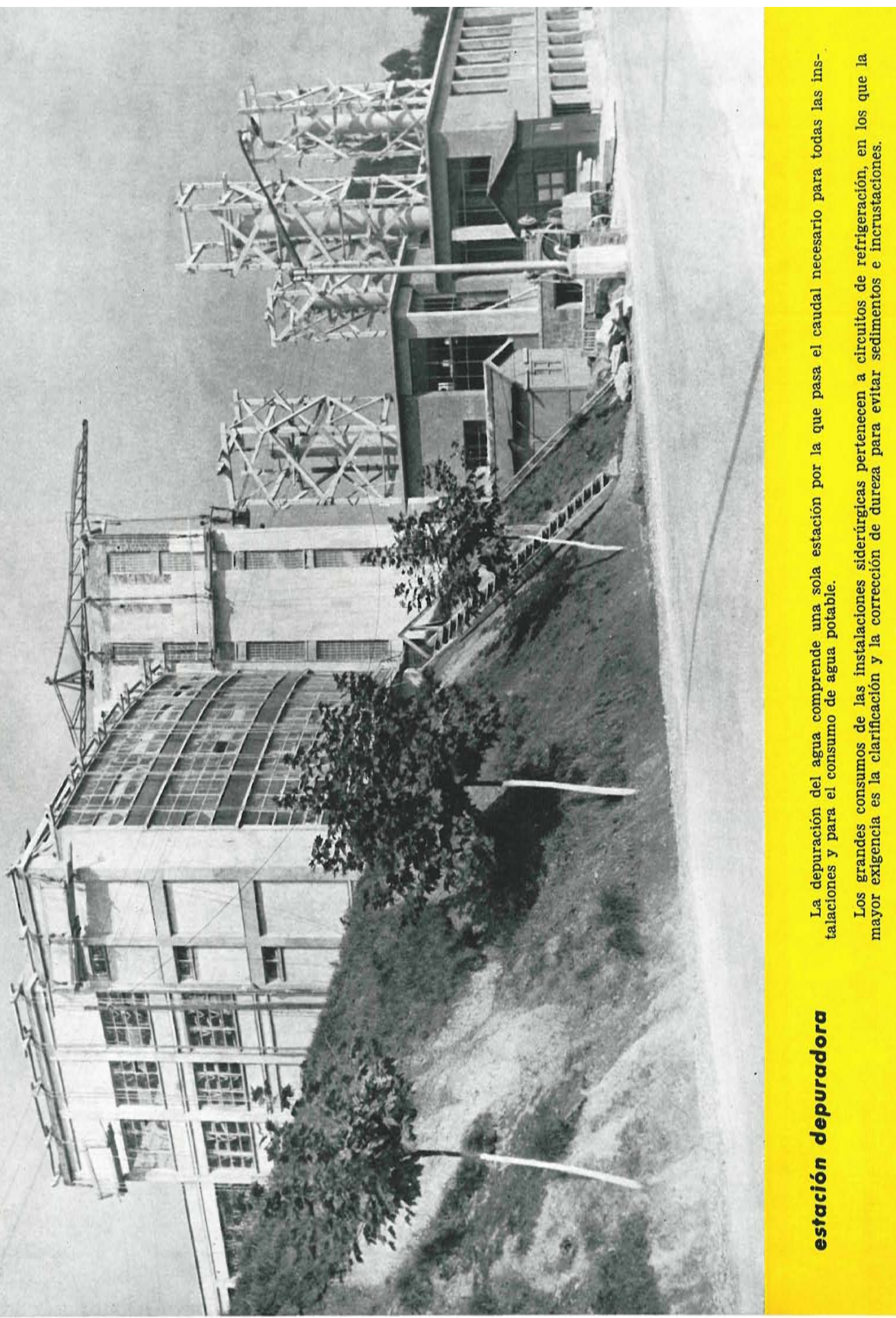




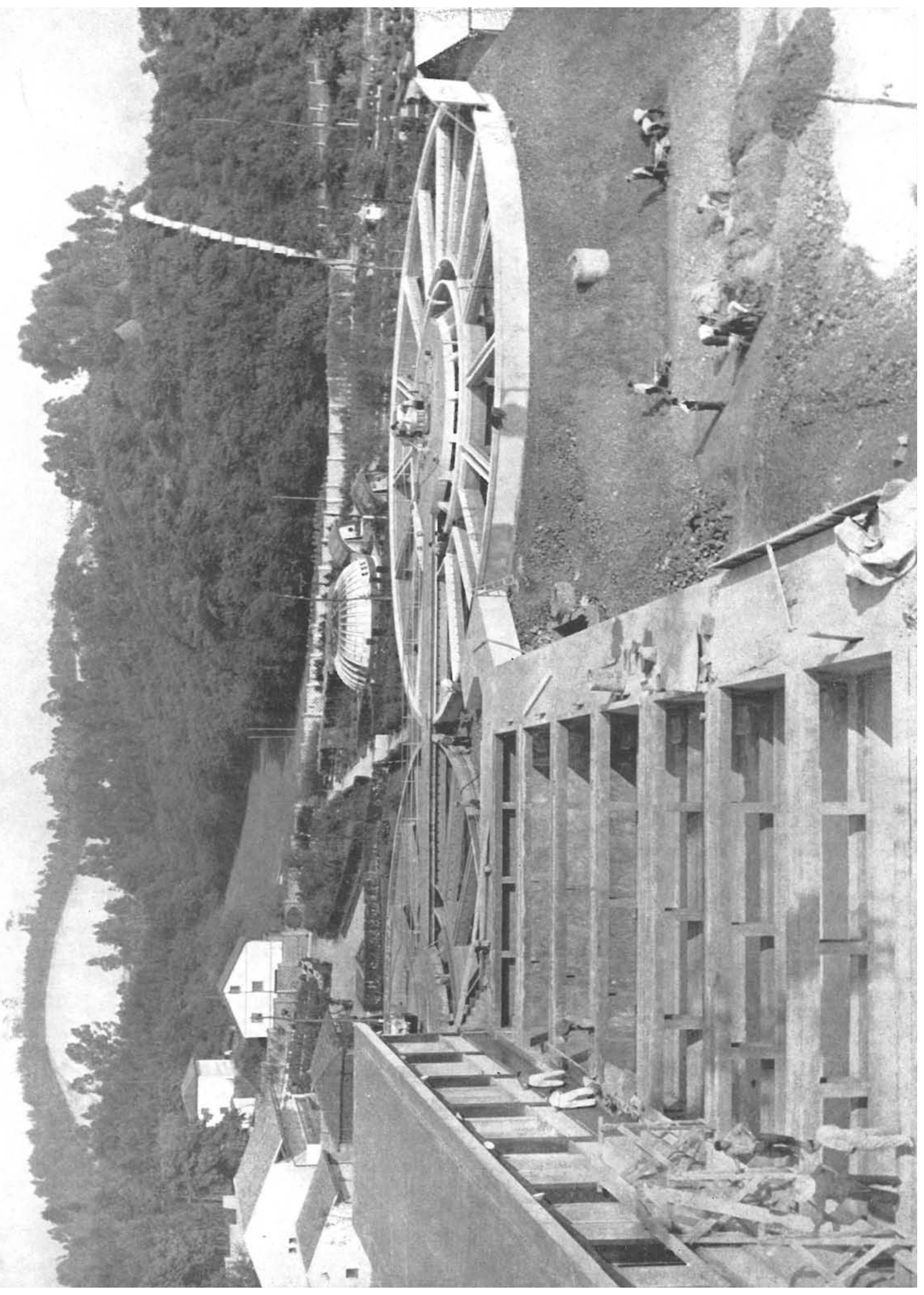




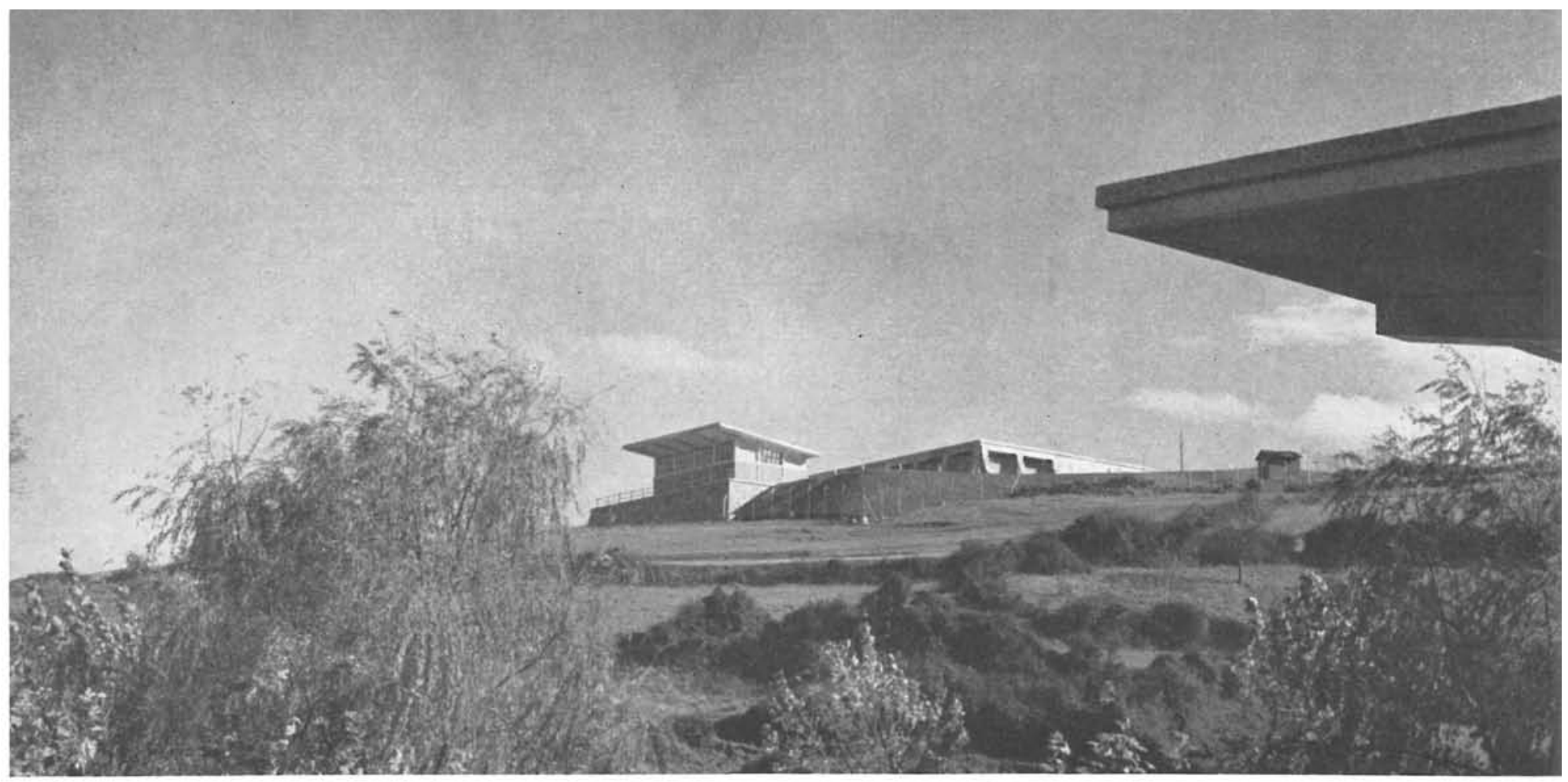

Ciertos servicios, como la Central Térmica y otros productores de vapor, que requieren mayor grado de depuración, pero con caudales pequeños, disponen de sus propios dispositivos especiales para llegar al alto grado de pureza necesario, que no sería práctico ni económico aplicar al total.

Y, por último, se completa la depuración físico-química con la esterilización bacteriológica, lo que simplifica las instalaciones y garantiza la seguridad sanitaria al menor costo.

La estación depuradora está situada fuera de la carretera norte, frente al final de las naves de Laminación, y su situación a media ladera permitió adoptar como cota del plano de agua la de $(21,00)$. Siendo de unos cuatro metros la pérdida de carga en la instalación, se dispone a la salida de la cota $(17,00)$, suficiente para llegar a cualquier punto de la red con los caudales previstos, que después las instalaciones deben bombear a medida de sus necesidades.

La llegada del agua a la Estación Depuradora puede obtenerse, por gravedad, con los embalses llenos y caudales moderados, pero con embalses bajos y caudales fuertes es necesario elevarla a la cota $(21,00)$, por lo que se ha dispuesto, junto a la Estación, una casa de bombas con este objeto.

Está previsto el suministro normal, total, a través de la Estación, con su esterilización, pero es posible dejar fuera de servicio aquélla, e incluso inyectar el agua de los embalses directamente a la red, en caso de averia o urgencia, estando, en ambas eventualidades, asegurada la esterilización mediante las adecuadas instalaciones.

La instalación del sistema de decantación acelerada y filtros rápidos de arenas ha sido proyectada, en su totalidad, para $2.400 \mathrm{l} / \mathrm{s}$, con dos baterías de 24 filtros, servidas por dos decantadores accelator de $28 \mathrm{~m}$ de diámetro cada una, y situadas a lo largo de la ladera, a ambos lados de un edificio central de control y dosificación. Por el momento sólo se ha construído una batería de filtros y sus dos accelators, con el edificio de control, y se ha montado el equipo de funcionamiento de 18 filtros y ambos accelators. Queda así asegurado el tratamiento de $600 \mathrm{l} / \mathrm{s}$ con una reserva de $50 \%$ en filtros y de $100 \%$ en los accelators.

En el caso de que no se consiga la llegada de agua a la Estación por gravedad, se ha construído una casa de bombas, en la cual se prevé la instalación, en última fase, de cinco bombas de $600 \mathrm{l} / \mathrm{s}$, y se han colocado como protección contra golpes de ariete chimeneas de equilibrio, no sólo del lado de la impulsión de las bombas, como es normal, sino también del lado de la aspiración, a causa de la gran longitud de tubería desde los embalses. 

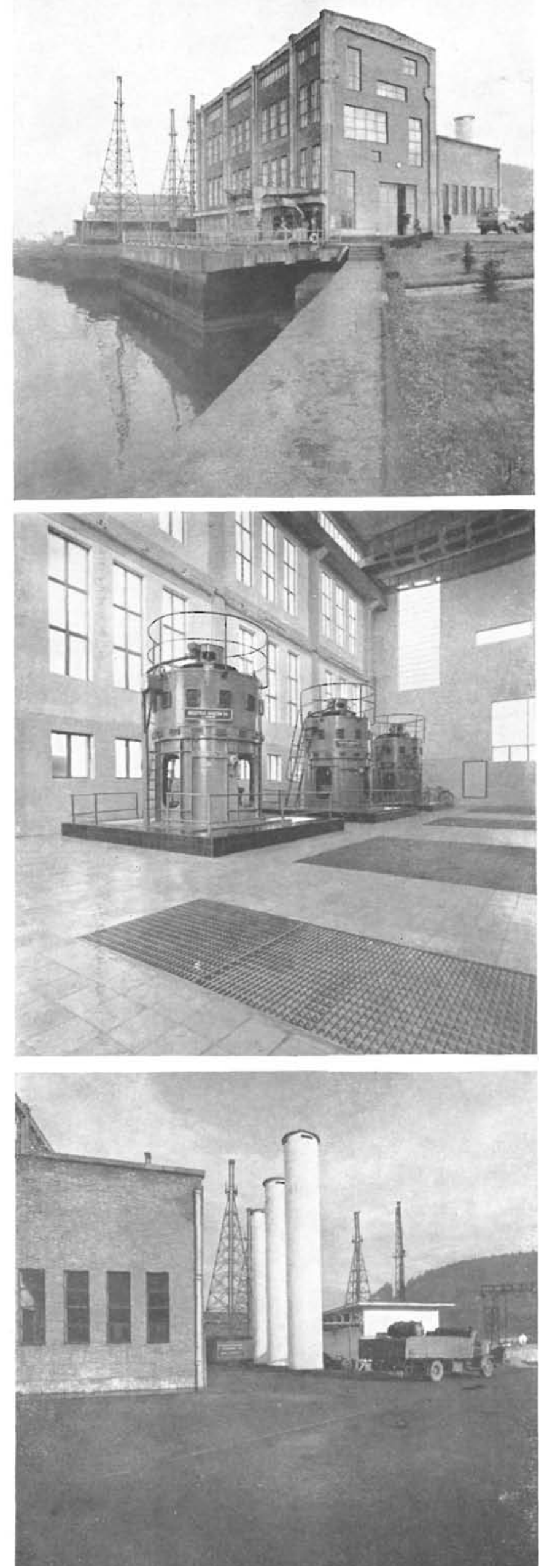

\section{abastecimiento de agua salada}

Las necesidades de refrigeración de la Central Térmica de $10 \mathrm{~m}^{3} / \mathrm{s}$ obligaron

a proyectar dicha refrigeración

con agua salada,

y la decisión de disponer de circuitos

cerrados

en la mayor parte de los departamentos aumentaron las necesidades de ésta

y el recorrido de las conducciones.

El proyecto realizado

consiste en una casa de bombas, una estación de clorado y filtrado,

y las conducciones

a los distintos usuarios.

La casa de bombas está dotada con tres bombas Kaplan, con capacidad para $4,5 \mathrm{~m}^{3} / \mathrm{s}$ cada una, accionadas por motores de $900 \mathrm{CV}$.

La elección de este tipo de bombas ha sido debida a la carrera de la marea, que hace variar constantemente la altura de aspiración de la misma, con las consiguientes variaciones de caudal, lo que permite con este tipo de bombas una regulación perfecta.

Las aguas son conducidas por tres tuberías de hormigón armado, de $1,40 \mathrm{~m}$ de diámetro y $200 \mathrm{~m}$ de longitud, hasta la estación de filtrado; anteriormente a la salida de las bombas,

el agua es clorada con el fin de eliminar la fauna, muy perjudicial

en los cambiadores de calor; en la estación de filtrado se han dispuesto dos tambores filtrantes que dejan el agua completamente apta para su uso.

Dos túneles gemelos de $700 \mathrm{~m}$ la conducen hasta una cámara de repartición,

los cuales distribuyen las aguas a la central térmica y a los distintos centros de refrigeración. Los canales son de hormigón armado, con secciones y espesores variables. La longitud de estos canales es de 2.200 metros. 
Las aguas, después de refrigerar en los cambiadores de calor, son devueltas en parte a la ría y en parte son utilizadas para apagado de escorias en horno alto, máquinas de colar lingotes, etc. Los canales de agua caliente tienen 1.600 metros de longitud.

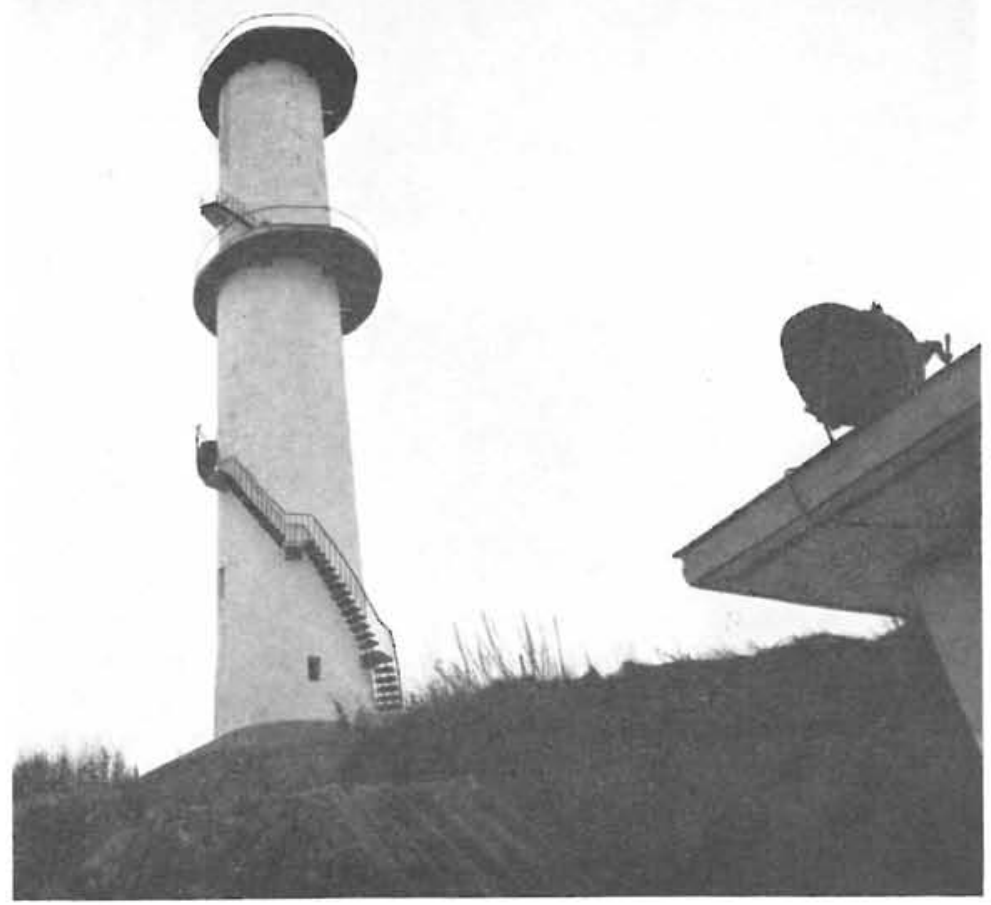



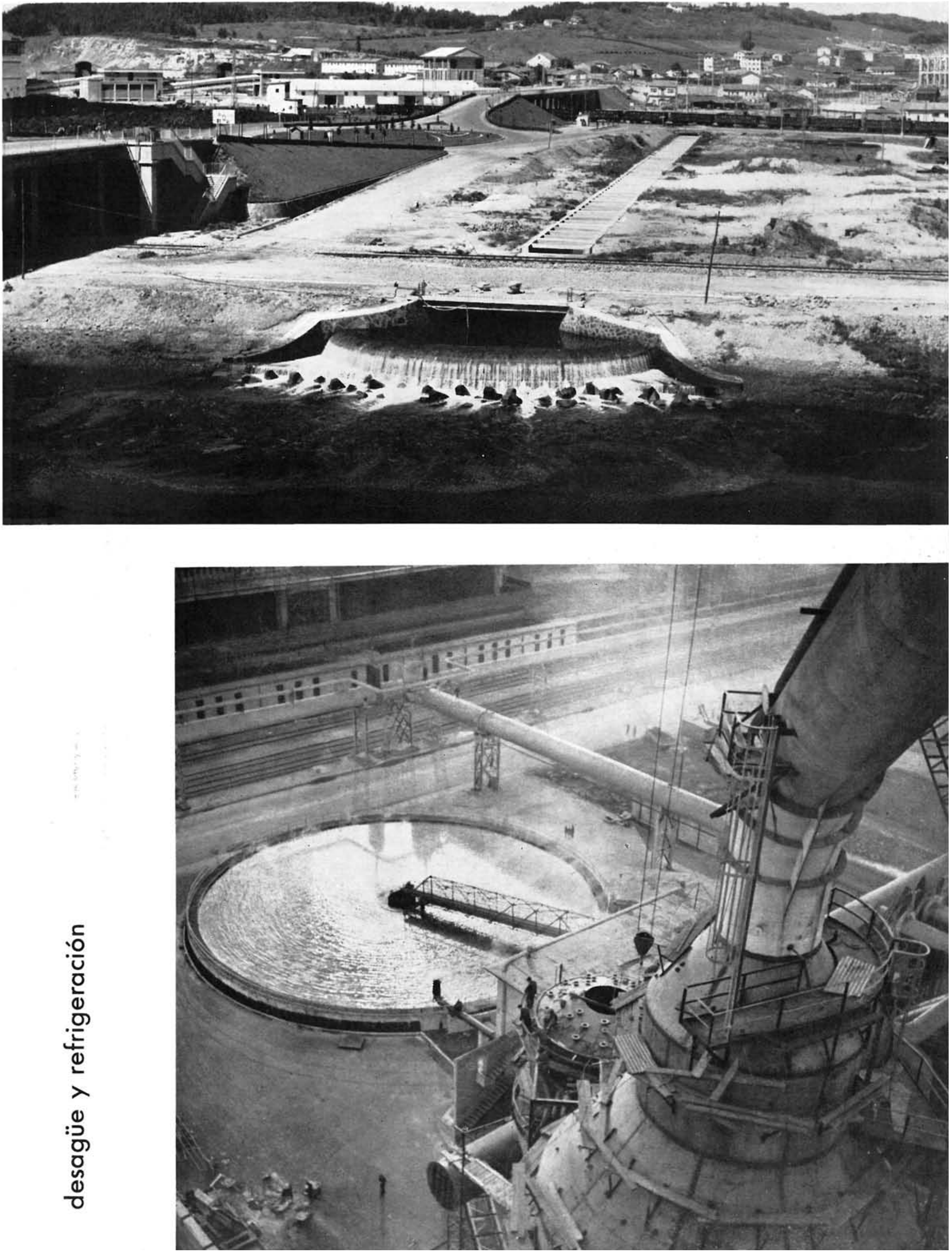


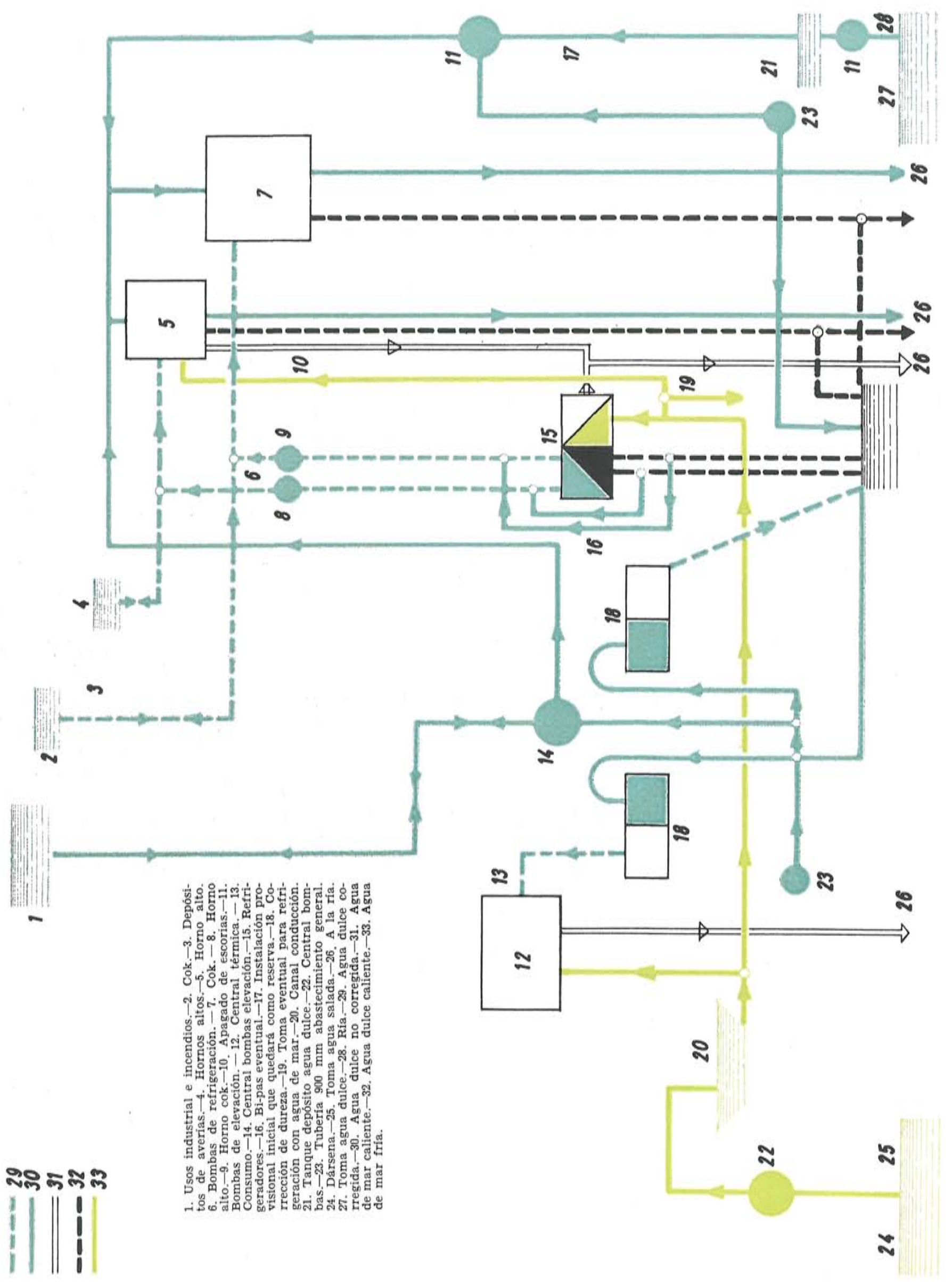

